\author{
Military Technical College \\ Kobry El-Kobbah, \\ Cairo, Egypt.
}

\author{
$16^{\text {th }}$ International Conference \\ on Applied Mechanics and \\ Mechanical Engineering.
}

\title{
WIND ENERGY MODELING OVER WEST AFRICA
}

\author{
D. M. Saleh ${ }^{1}$, G. El-Afandi ${ }^{2}$ and R. M. Hassan ${ }^{3}$
}

\begin{abstract}
Wind Energy remains one of the few bright spots in renewable energy in the $21^{\text {st }}$ Century. Wind farms can provide clean, renewable energy to homes, businesses and the agricultural sector. Though Wind energy is the fastest growing component of renewable energy sources, it is highly fluctuating in time and space due to the intermittent nature of near-surface winds. Understanding of uncertainties in shortterm prediction of wind energy is becoming increasingly important for a variety of issues, such as integration into an electricity supply system, local energy balancing, and management of energy resources. To overcome the shortfall of high resolution in-situ regional wind observations for wind resources assessment in West Africa, the wind conditions have been estimated utilizing the next-generation mesoscale numerical weather prediction system, the Weather Research and Forecasting (WRF) Model. The main aim of this study is to evaluate the performance of (WRF) Model in wind prediction over two regions in West Africa. The present case study shows that the model has performed reasonably well over Dakar, Senegal. On the other hand, the model performance over Ouagadougou, Burkina Faso was unsatisfactory.
\end{abstract}

\section{KEY WORDS}

Wind energy, WRF, Modeling, West Africa

1 Graduate student, Dpt. of Environmental Science, Tuskegee University, Tuskegee, Alabama, USA.

2 Professor, Dpt. of Environmental Science, Tuskegee University, Tuskegee, Alabama, USA.

3 Graduate student, Dpt. of Environmental Science, Tuskegee University, Tuskegee, Alabama, USA. 


\section{INTRODUCTION}

West Africa, a region larger than Western Europe, and covering a population of almost 300M people, is one of the most power-deficient parts of the world. The developing nations of Africa are popular locations for the application of renewable energy technology. Currently, many nations already have small-scale solar and wind, providing energy to urban and rural populations. These types of energy production are especially useful in remote locations because of the expensive cost of transporting electricity from large-scale power plants. The application of renewable energy technology has the potential to resolve many of the problems that face Africans every day. Though a high resolution in-situ regional wind observations are required for the assessment of wind resources in order to get access to wind energy as Wind energy is highly fluctuating in time and space due to the intermittent nature of near-surface winds[1], There is a shortfall of high resolution in-situ regional wind observations data in West Africa (Figure1).The objective of this study is to estimate the wind component, utilizing the next-generation mesoscale numerical weather prediction system, the Weather Research and Forecasting (WRF) Model. The estimated modeled wind has been validated against observed wind data obtained from two weather stations in West Africa.

\section{NUMERIC WEATHER PREDICTION (NWP)}

Several physical models have been developed based on using weather data with sophisticated meteorological for wind speed forecasting and wind energy predictions [2][3]. These models take into accounts several factors including shelter from obstacles, local surface roughness and its changes, and effects of orography, speed up or down, scaling of the local wind speed within wind farms, wind farm layouts and wind turbines power curves. The NWP system usually provides wind speed forecasts for a grid of surrounding points around the wind generators. According to the type of NWP system, these forecasts are given with a spatial resolution. The physical approach uses a meso-scale or micro-scale model for the downscaling, which interpolate these wind speed forecasts to the level of the wind generators [4]. For running the downscaling models, it is necessary to have a detailed description of the terrain surrounding the wind generators. However, collecting the information of terrain conditions is one of the main difficulties in the implementation of physical models. Several more sophisticated flow modeling tools, such as mesoscale meteorological model (MM5), CFD, have been used for the wind speed prediction. These advanced models have the potential to improve the modeling of the wind flow, particularly in complex terrain. However, further validation work and more computer power are required before these models are use. Since NWP models are complex mathematical models, they are usually run on super computers, which may limits the advantage of NWP methods.

Therefore, the performance of physical models is often satisfactory for long (larger than 6 hours ahead) time horizons and they are on the other hand inappropriate for short-term prediction (several minutes to one hour) alone due to difficulty of information acquisition and complicated computation. An unstable atmospheric condition can lead to very poor numerical weather predictions and thus to inaccurate wind energy ones. In contrast, as the atmospheric situation is stable, one can expect 
more accurate predictions for wind energy because wind speed is the most sensible input to wind energy prediction models. In general, a common approach to shortterm wind energy prediction is to enhance the output of numerical weather prediction (NWP) models operated by weather services to obtain the local wind data [5].

\section{WRF MODELING SYSTEM}

The Weather Research and Forecasting (WRF) model is a numerical weather prediction (NWP) and atmospheric simulation system developed for both research and operational applications and is a supported "community model", that is, a free and shared resource with distributed development and centralized support[6]. Its development is led by the National Center for Atmospheric Research (NCAR), the National Oceanic and Atmospheric Administration (represented by the National Centers for Environmental Prediction (NCEP) and the (then) Forecast Systems Laboratory (FSL)), the Air Force Weather Agency (AFWA), the Naval Research Laboratory, the University of Oklahoma, and the Federal Aviation Administration (FAA). The Advanced Research WRF (ARW) dynamical core has an equation set which is fully compressible, Eulerian and non- hydrostatic with a run-time hydrostatic option [7]. It is conservative for scalar variables. The model uses terrain-following, hydrostatic-pressure vertical coordinate with the top of the model being a constant pressure surface. The model supports both idealized and real-data applications with various lateral boundary condition options. The model also supports one-way, twoway, and moving nest options [8].

\section{EXPERIMENT DESIGN AND MODEL SETUP}

- The WRF model (version 3.4.1) will be configured with three domains using two-way nesting with a horizontal resolution of $9 \mathrm{KM}$ at the first domain, $3 \mathrm{KM}$ at the second domain and $1 \mathrm{~km}$ at third domain as shown in (Figure2). http://www.mmm.ucar.edu/wrf/users/downloads.htm

- The initial and lateral boundary meteorological data used to run the model, have been downloaded from the National Centers for Environmental Prediction (NCEP), global final analyses on $1^{\circ} \times 1^{\circ}$ degree from Global Forecasting System (GFS) and it is updated every six hours. http://rda.ucar.edu/datasets/ds083.2

- In the present study a 72 hours wind simulation using WRF has been produced, the maximum and minimum daily wind speed and the maximum daily wind during the have been simulated four times during the year 2012 for each site with a total of 576 hours of simulation for each of the selected sites; 1- Coastal station; Dakar, Senegal (14.3N, 17.63W).

2- Inland station; Ouagadougou, Burkina Faso (12.35N, 1.51W).

- The data used for validation of surface wind is derived from: The observations are taken using standards techniques and practices as laid out by WMO [9]. http://www.ncdc.noaa.gov 


\section{STUDY AREA}

First site (DAKAR-Senegal); it is located on the Cap-Vert Peninsula on the Atlantic coast and is the westernmost city on the African mainland (14.3N, 17.63W). Its elevation above sea level is 24 meters. Dakar has a hot semi-arid climate with a short rainy season and a lengthy dry season. Dakar's rainy season lasts from July to October while the dry season covers the remaining eight months. The climate of Dakar is very much influenced by the marine trade winds and the monsoon which respectively blow in the region from November to June and from July to October in the direction of N-NW and S.SE [10].

Second site (Ouagadougou-Burkina Faso); it is located on the central plateau $\left(12.35^{\circ} \mathrm{N} 1.5^{\circ} \mathrm{W}\right)$. Its elevation above sea level is 306 meters. The climate of Ouagadougou consists of a dry period from October to April with wind blowing in from the Sahara in the north and north-east, and a wet period from May to September averaging $700 \mathrm{~mm}$ of rain. Average daily temperatures range from $25^{\circ} \mathrm{C}$ to $33^{\circ} \mathrm{C}[11]$.

\section{RESULTS AND DISCUSSION}

Statistical measures such as Pearson correlation ( $r$ ), Root Mean Squared Error (RMSE) and Fractional Bias (FB) have been used for evaluation of model performance $[12,13]$. Statistical analysis of wind speed has been performed for estimations at both stations Dakar and Ouagadougou for maximum wind conditions in Tables 1a \& $2 a$ and minimum wind conditions Tables 1b-2b., general tendency by the model to over predict wind speed is observed in all the different times through the year which has also been observed in many earlier studies [14, 15, 16]. Performance of WRF is Satisfactory over Dakar (Figs. 3a \& 3b)with acceptable to good correlation $(r)$ and RMSE performance regarding wind speed except in the case of 27-29/07/2012-Table 1a, where the WRF model has a poor correlation due to sporadic wind in that day where the wind speed exceeds $15 \mathrm{~m} / \mathrm{s}$ for only one observation which can be difficult to model in terms of intensity and timing[17], but the performance of the model is unsatisfactory over Ouagadougou regarding wind speed and direction, with a poor correlation( $r$ ) in almost all the cases(Maximum and Minimum conditions), that can be attributed to the short fall of the continuous observed hourly data during the simulation periods, in addition to the effect of the thermal wind system[11] which can cause a large variability in wind speed and direction Thus wind sensitivities tend to have more "noise"(Figs. 4a \& 4b). Wind direction, being an angular quantity, has not been analyzed statistically because statistical measures are based on arithmetic difference between observed and estimated quantities which is not applicable for vector parameters like wind direction [6], however, it can be noted that WRF model performance is very satisfactory in regards to wind direction in Dakar, Senegal in both maximum and minimum conditions (Figure 5a \& Figure 5b). WRF model performance is not satisfactory in regards to wind direction in Ouagadougou, Burkina Faso in both maximum and minimum conditions (Figure 6a \& Figure 6b). 


\section{CONCLUSION}

The present case study shows that the model performance is satisfactory over Dakar, Senegal. Furthermore, with more studies conducted, model biases can be determined and adjusted for, as in any forecasting tool. Performance over Ouagadougou, Burkina Faso is unsatisfactory .More studies with different physics options applicable in WRF model may lead to better agreement between both modeled and observed wind Data.

\section{REFERENCES}

[1] Giebel, G., Badger, J., Landberg, L., Nielsen, H., Nielsen, T., Madsen, H., Sattler, K., Feddersen, H., Vedel, H.,Tøfting, J., Kruse, L., Voulund, L., 2005. Wind Power Prediction using Ensembles. Technical report, Riso National Laboratory. Risø-R-1527.

[2] L. Landberg, "A Mathematical Look at a Physical Power Prediction Model", Wind Energy Volume: 1, Issue: 1, September 1998, pp. 23 -28.

[3] Jing-Shan Hong, "Evaluation of the high-resolution model forecasts over the Taiwanarea during GIMEX", Weather and Forecasting, Vol. 18, 2003, pp.836846.

[4] G. Kariniotakis et al., "The State of the Art in Short-term Prediction of Wind Power -From an Offshore Perspective", in Proc. of 2004 SeaTechWeek, Brest, France, 20-21Oct. 2004.

[5] Gnana Sheela, K. "Computing models for wind speed prediction in renewable energy systems." IJCA Special Issue on "Computational Science, New Dimensions \& Perspectives NCCSE (2011)

[6] Mohan, Manju, and Shweta Bhati. "Analysis of WRF model performance over subtropical region of Delhi, India." Advances in Meteorology 2011 (2011).

[7] Borge, Rafael, et al. "A comprehensive sensitivity analysis of the WRF model for air quality applications over the Iberian Peninsula." Atmospheric Environment42.37 (2008): 8560-8574.

[8] National Centre for Atmospheric Research (NCAR), ARW Version 3 Modeling System's User's Guide, NCAR, Boulder, Colo, USA, 2010.

[9] WMO Guide to Meteorological Instruments and Methods of Observation,http://www.wmo.int/pages/prog/www/IMOP/publications/CIMOGuide/CIMO_Guide-7th_Edition-2008.html.

[10] http://www.unep.org/dewa/water/groundwater/africa/english/reports/CountrySu mmaries/Senegal/Eng-Senegal-Summary.pdf.

[11] Lindén, Jenny. "Nocturnal cool island and a thermal wind-system-two features of the local climate in Ouagadougou, Burkina Faso." The seventh International Conference on Urban Climate. Yokohama, Japan. 2009.

[12] J. J. Cassano and M. E. Higgins, "Development of a regional arctic climate system model: performance of WRF for regional pan-Arctic atmospheric simulations," in Proceedings of the 11th WRF Users' Workshop National Center for Atmospheric Research, Boulder, Colo, USA, 2010.

[13] T. Prabha and G. Hoogenboom, "Evaluation of the Weather Research and Forecasting model for two frost events," Computers and Electronics in Agriculture, vol. 64, no. 2, pp. 234-247, 2008. View at Publisher · View at Google Scholar 
[14] R. Borge, V. Alexandrov, J. José del Vas, J. Lumbreras, and E. Rodríguez, "A comprehensive sensitivity analysis of the WRF model for air quality applications over the Iberian Peninsula, "Atmospheric Environment, vol. 42, no. 37, pp. 8560-8574, 2008. View at Publisher · View at Google Scholar . View at Scopus.

[15] J. H. Kwun, Y. K. Kim, J. W. Seo, J. H. Jeong, and S. H. You, "Sensitivity of MM5 and WRF mesoscale model predictions of surface winds in a typhoon to planetary boundary layer parameterizations," Natural Hazards, vol. 51, no. 1, pp. 63-77, 2009. View at Publisher - View at Google Scholar · View at Scopus

[16] J. J. Ruiz, C. Saulo, and J. Nogués-Paegle, "WRF model sensitivity to choice of parameterization over South America: validation against surface variables," Monthly Weather Review, vol. 138, no. 8, pp. 3342-3355, 2010. View at Publisher · View at Google Scholar.

[17] Clifford, Kevin T.WRF-model performance for wind power forecasting in the coast ranges of central California. San Jose State University, 2011. 
Table 1a. Statistical evaluation of Maximum wind simulations, Dakar.

\begin{tabular}{|l|c|c|c|c|}
\hline Date & $\mathbf{1 9 - 2 1 / 0 1 2 0 1 2}$ & $\mathbf{2 7 - 2 9 / 0 4 / 2 0 1 2}$ & $\mathbf{2 7 - 2 9 / 0 7 / 2 0 1 2}$ & $\mathbf{1 3 - 1 5 / 1 1 / 2 0 1 2}$ \\
\hline RMSE & 1.54 & 0.97 & 2.15 & 1.21 \\
\hline r & 0.65 & 0.74 & -0.05 & 0.5 \\
\hline FB & -0.095 & -0.049 & -0.136 & -0.071 \\
\hline
\end{tabular}

Table 1b. Statistical evaluation of Minimum wind speed simulations, Dakar.

\begin{tabular}{|l|c|c|c|c|}
\hline Date & $\mathbf{0 8 - 1 0 / 0 1 / 2 0 1 2}$ & $\mathbf{2 0 - 2 2 / 0 4 / 2 0 1 2}$ & $\mathbf{1 7 - 1 9 / 0 7 / 2 0 1 2}$ & $\mathbf{0 9 - 1 1 / 1 1 / 2 0 1 2}$ \\
\hline RMSE & 1.03 & 0.96 & 1.2 & 1.4 \\
\hline R & 0.66 & 0.73 & 0.63 & 0.7 \\
\hline FB & -0.03 & -0.07 & 0.2 & -0.16 \\
\hline
\end{tabular}

Table 2a. Statistical evaluation of Maximum wind speed simulations, Ouagadougou.

\begin{tabular}{|l|c|c|c|c|}
\hline Date & $\mathbf{0 5 - 0 7 / 0 2 / 2 0 1 2}$ & $\mathbf{2 4 - 2 6 / 0 5 / 2 0 1 2}$ & $\mathbf{2 0 - 2 2 / 0 6 / 2 0 1 2}$ & $\mathbf{0 3 - 0 5 / 1 2 / 2 0 1 2}$ \\
\hline RMSE & 1.4 & 0.09 & 2.4 & 1.37 \\
\hline R & 0.41 & 0.17 & -0.37 & 0.43 \\
\hline FB & -0.062 & 0.09 & -0.13 & -0.15 \\
\hline
\end{tabular}

Table 2b. Statistical evaluation of Minimum wind speed simulations, Ouagadougou

\begin{tabular}{|l|c|c|c|c|}
\hline Date & $\mathbf{6 - 8 / 0 2 / 2 0 1 2}$ & $\mathbf{5 - 7 / 4 / 2 0 1 2}$ & $\mathbf{2 4 - 2 6 / 0 8 / 2 0 1 2}$ & $\mathbf{1 7 - 1 9 / 1 2 / 2 0 1 2}$ \\
\hline RMSE & 1.3 & 2.1 & 1.3 & 1.1 \\
\hline R & 0.5 & 0.4 & 0.4 & 0.26 \\
\hline FB & -0.31 & -0.17 & -0.14 & -0.12 \\
\hline
\end{tabular}




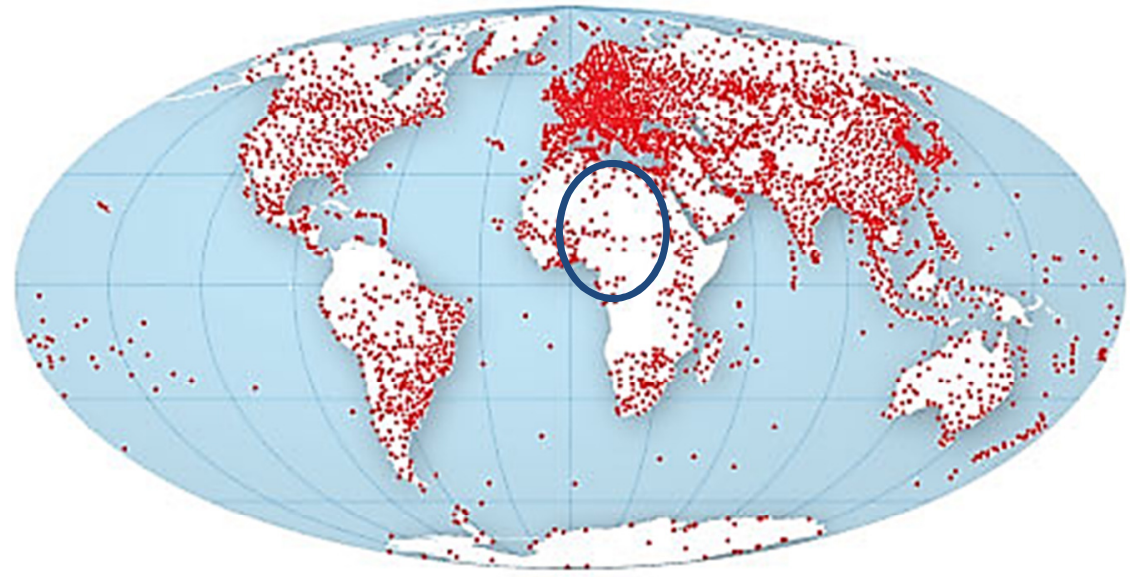

SOURCE: WORLD METEOROLOGICAL ORGANISATION

Fig. 1. Location of the world's key weather stations shows huge areas where information is not gathered.

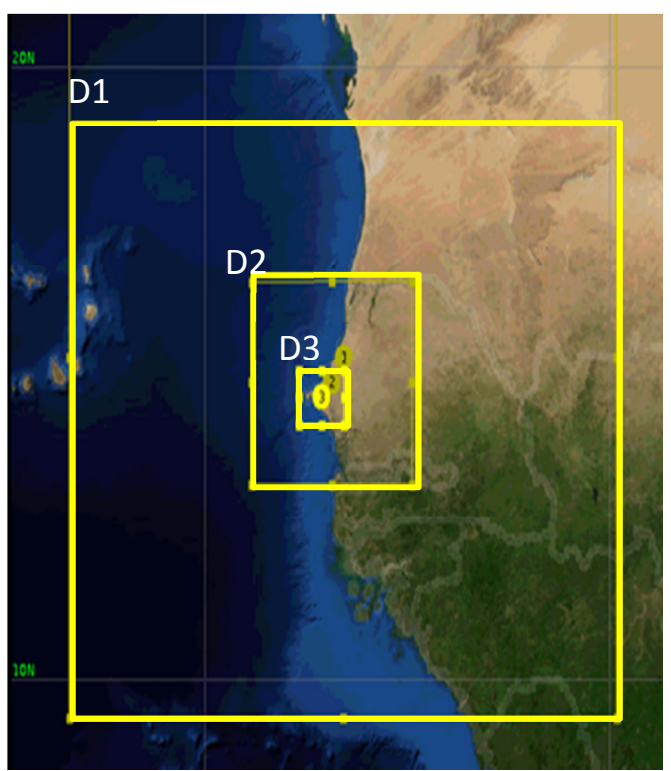

Dakar, Senegal

Dakar, Senega

$(14.3 \mathrm{~N}, 17.63 \mathrm{~W})$

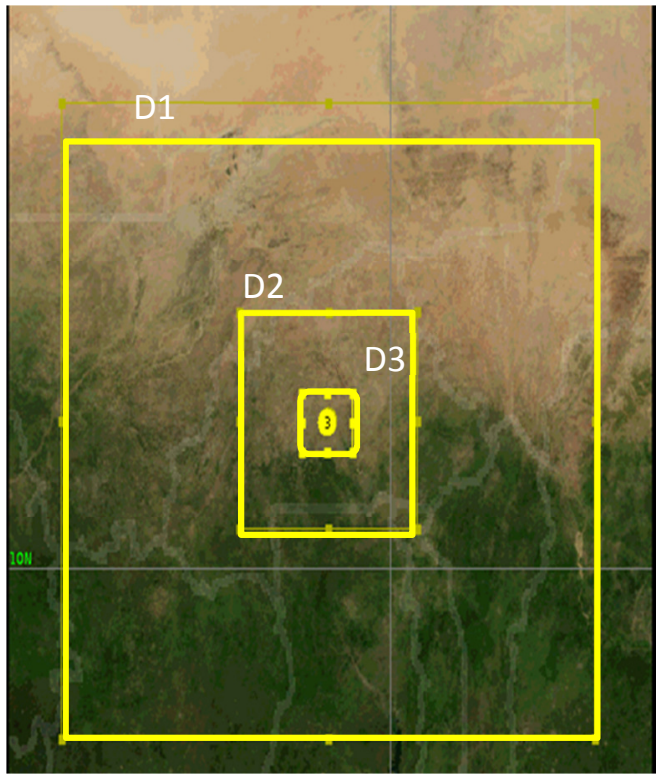

Ouagadougou ,Burkina Faso

Ouagadougou ,Burkina Faso

$(12.35 \mathrm{~N}, 1.51 \mathrm{~W})$

Figure 2. 3 nested domains. 

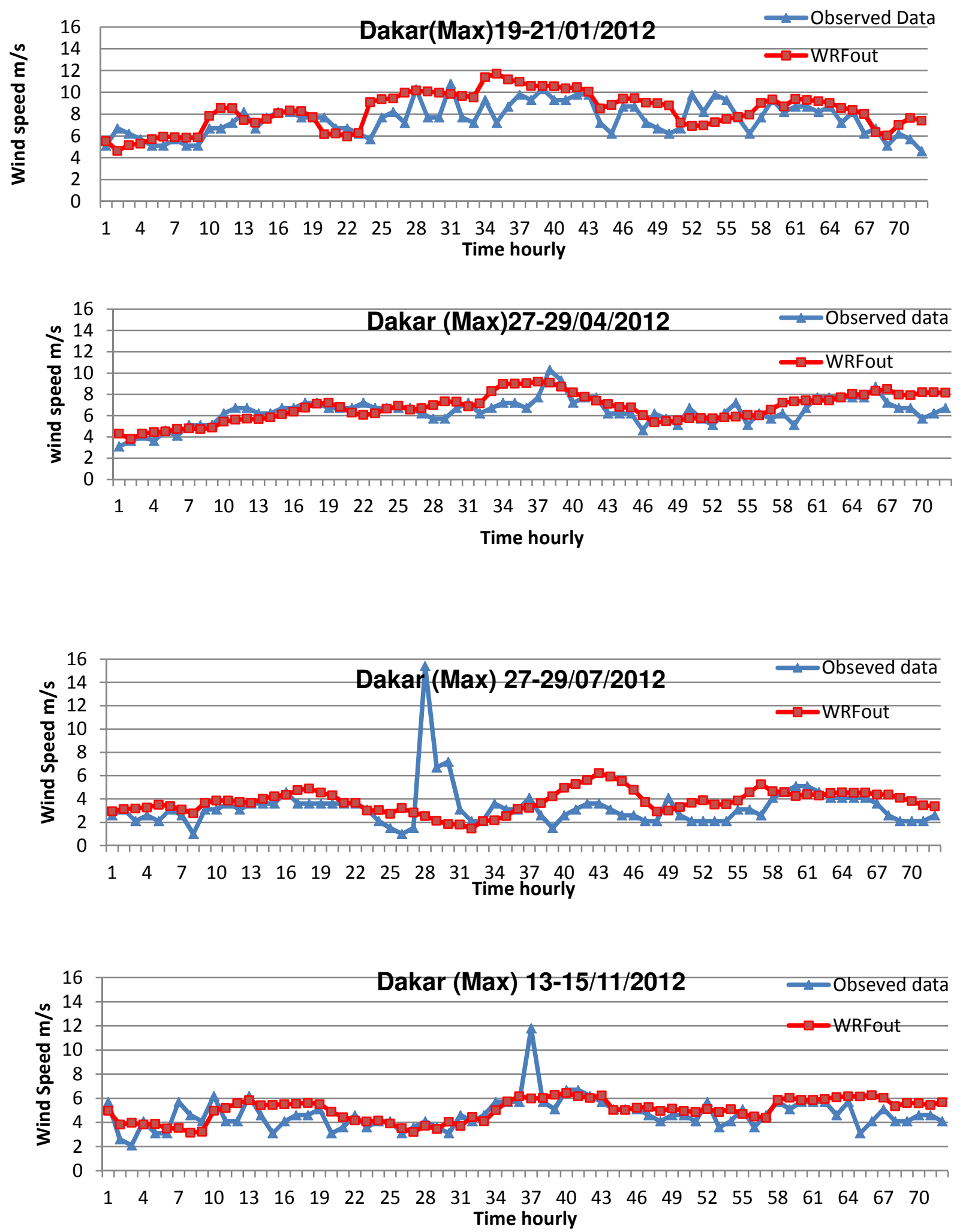

Fig. 3a. Comparison of difference between observed and estimated maximum wind speed at four different times through the year 2012 for Dakar, Senegal. 

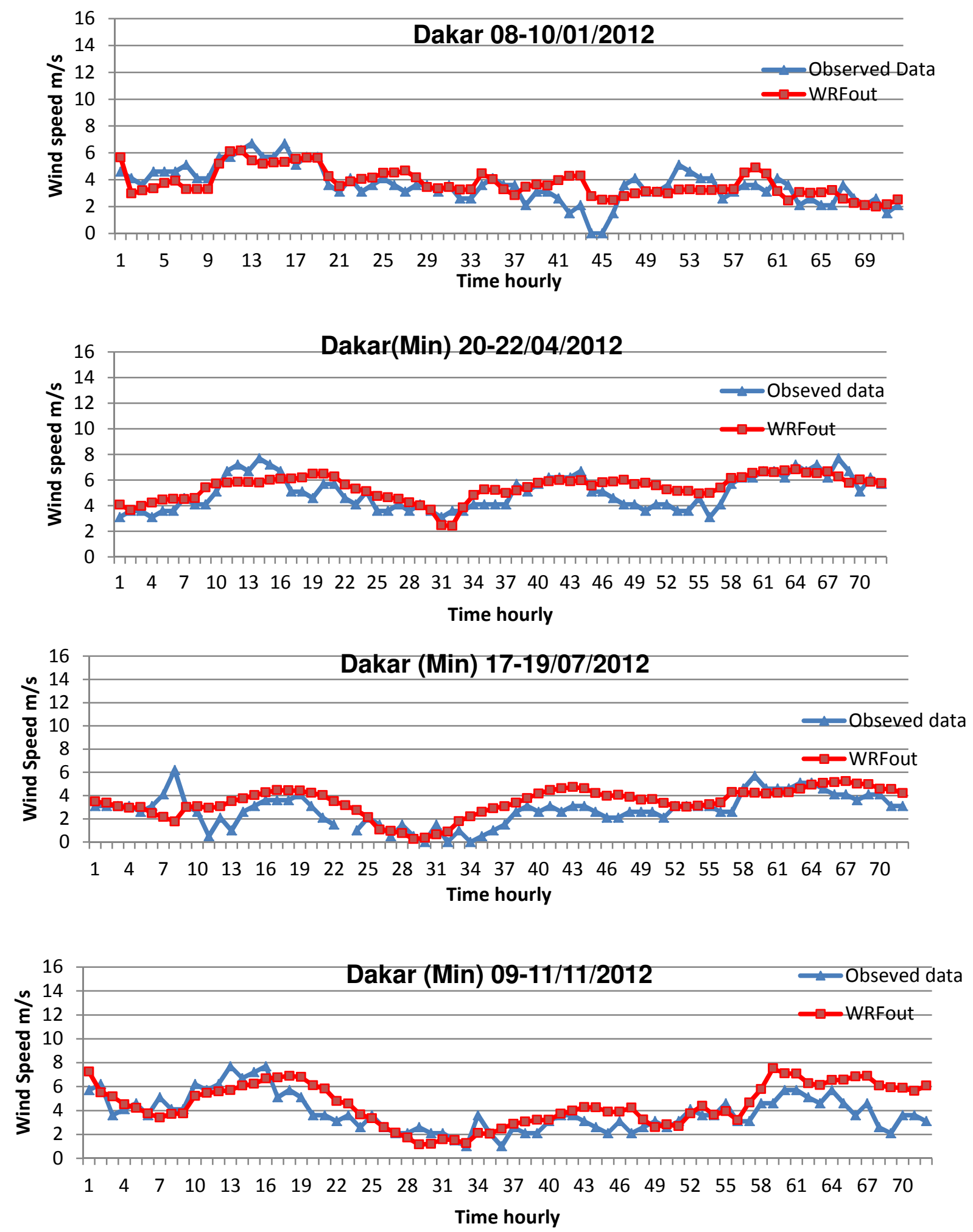

Fig. 3b. Comparison of difference between observed and estimated minimum wind speed at four different times through year 2012 for Dakar, Senegal. 

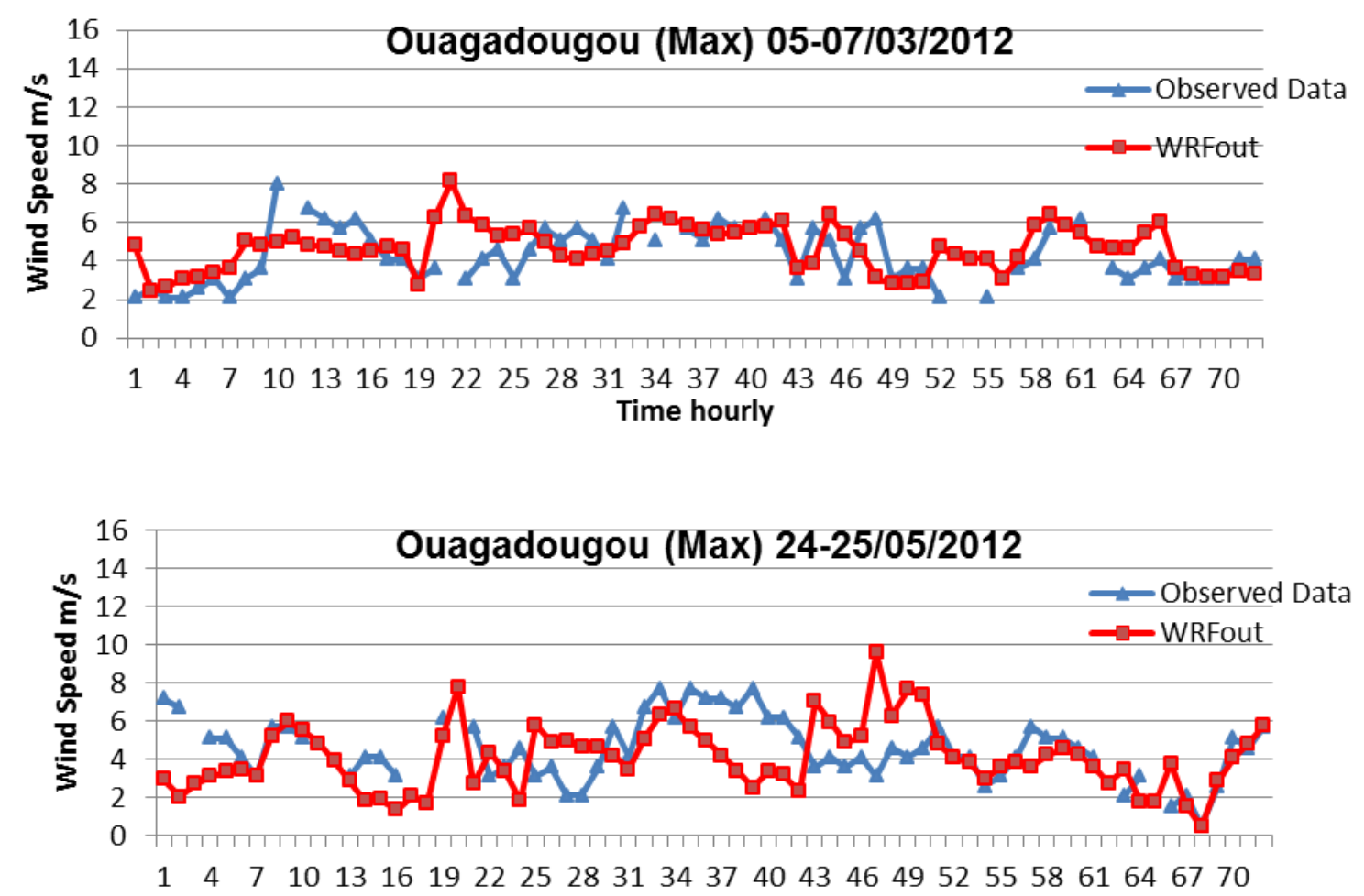

Time hourly
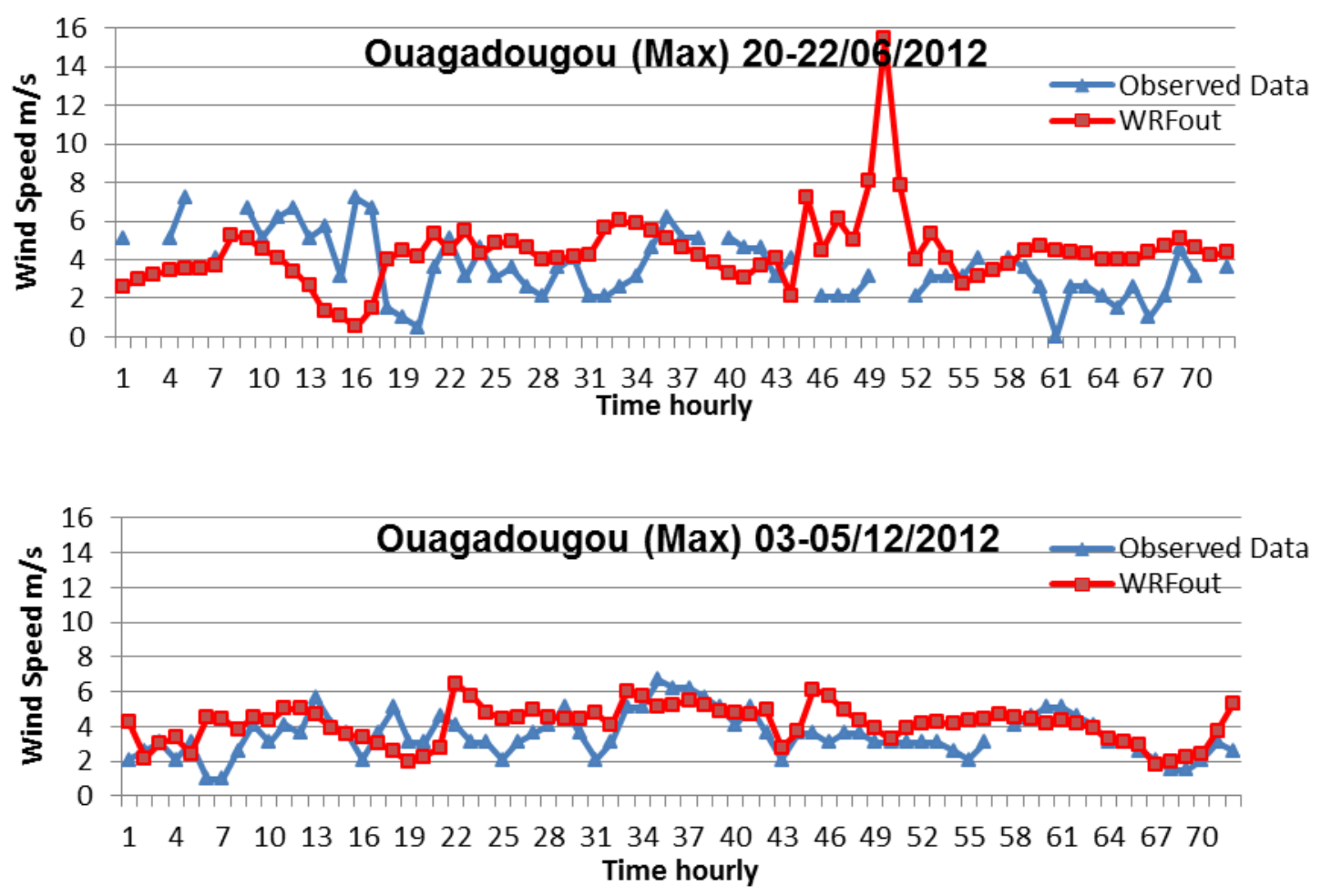

Fig. 4a. Comparison of difference between observed and estimated maximum wind speed at four different times through year 2012 for Ouagadougou, Burkina Faso 

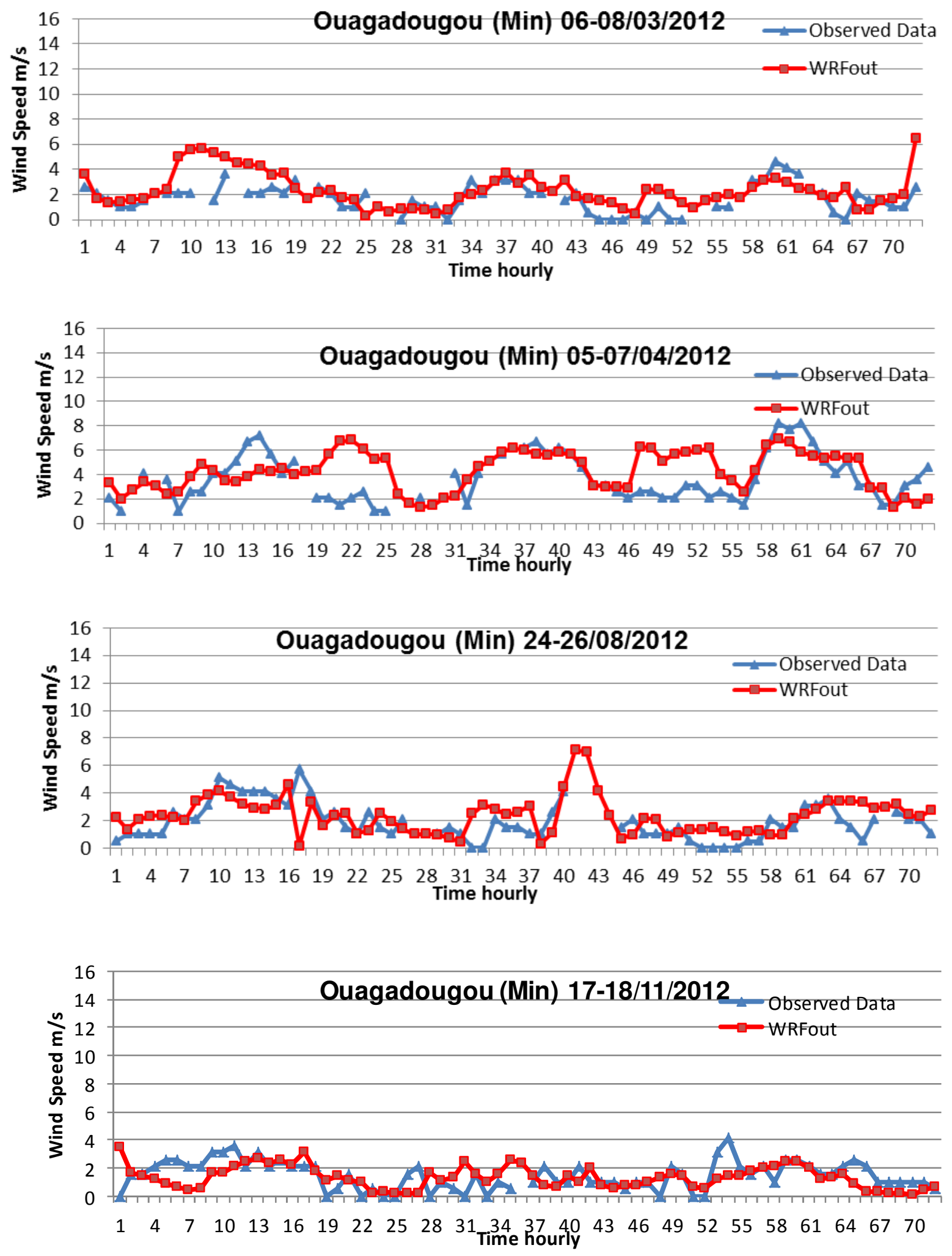

Fig. 4b. Comparison of difference between observed and estimated minimum wind speed at four different times through year 2012 for Ouagadougou, Burkina Faso 


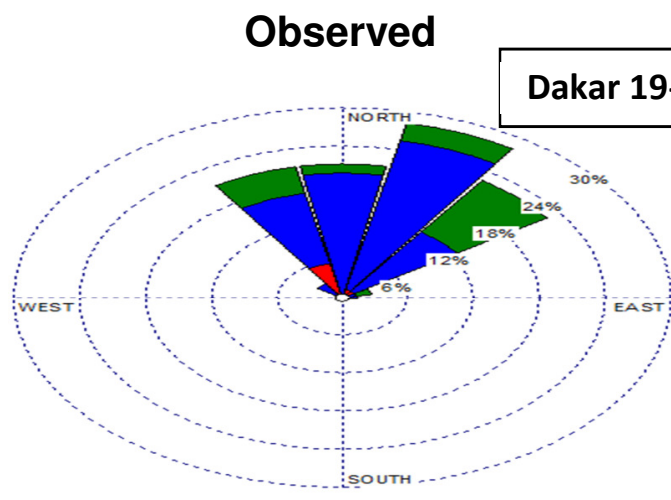

\section{Estimated}
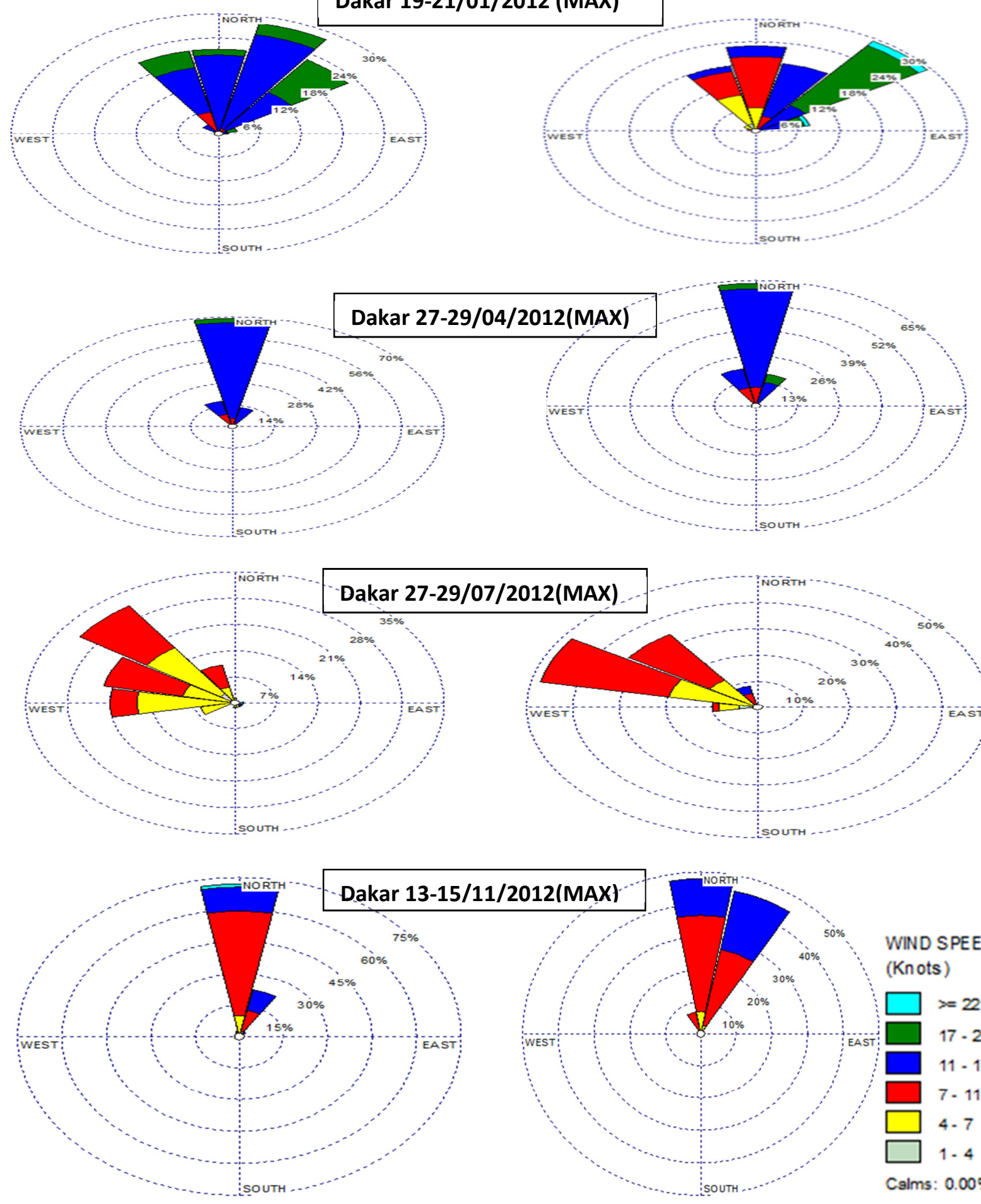

WIND SPEED (Knots)

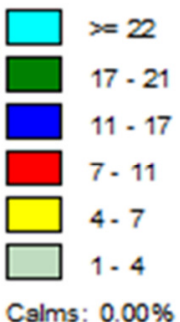

Fig. 5a. Comparison of difference between observed and estimated maximum wind speed and direction at four different times through the year 2012 for Dakar, Senegal using a wind rose plot. 

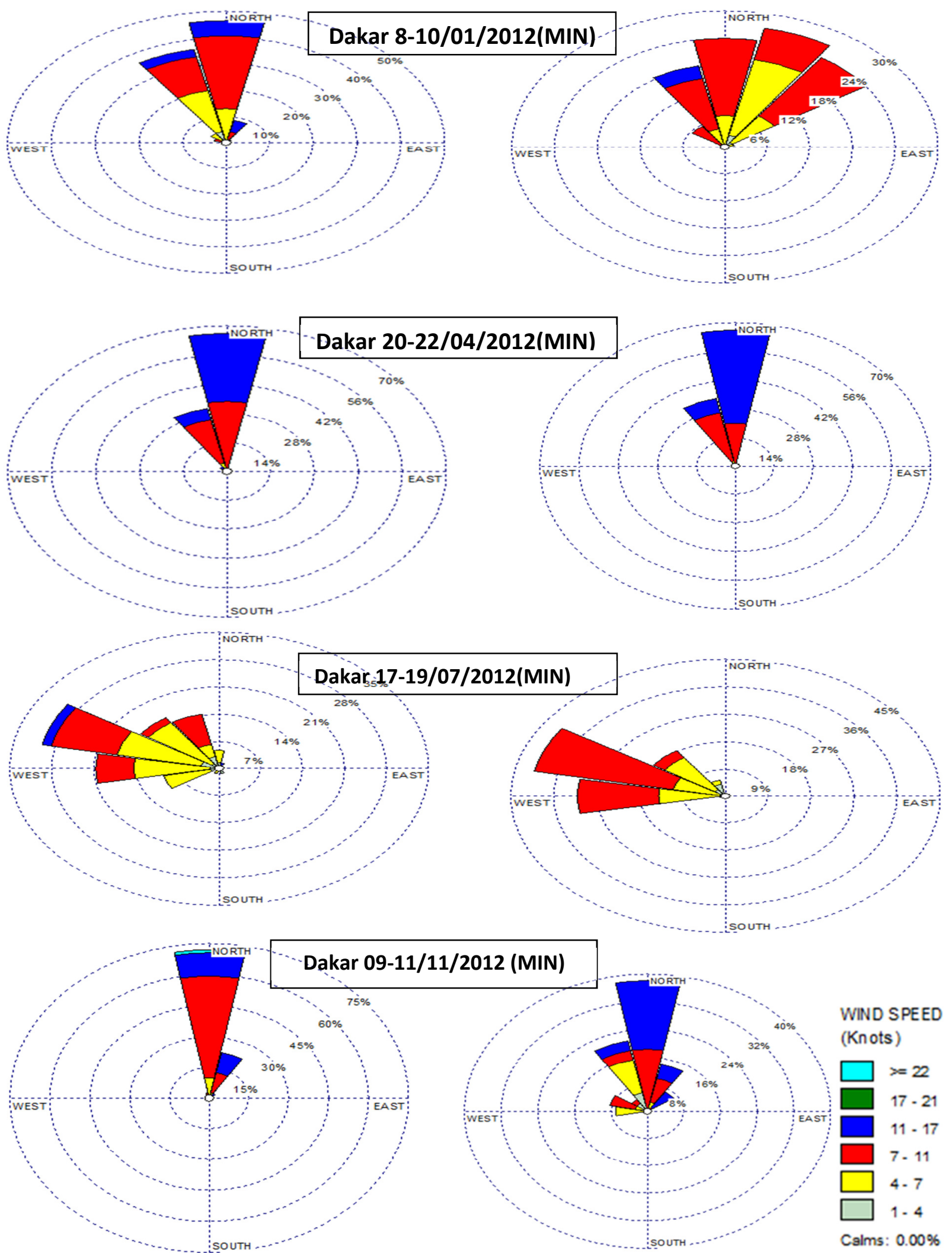

Fig. 5b. Comparison of difference between observed and estimated minimum wind speed and direction at four different times through the year 2012 for Dakar, Senegal using a wind rose plot 

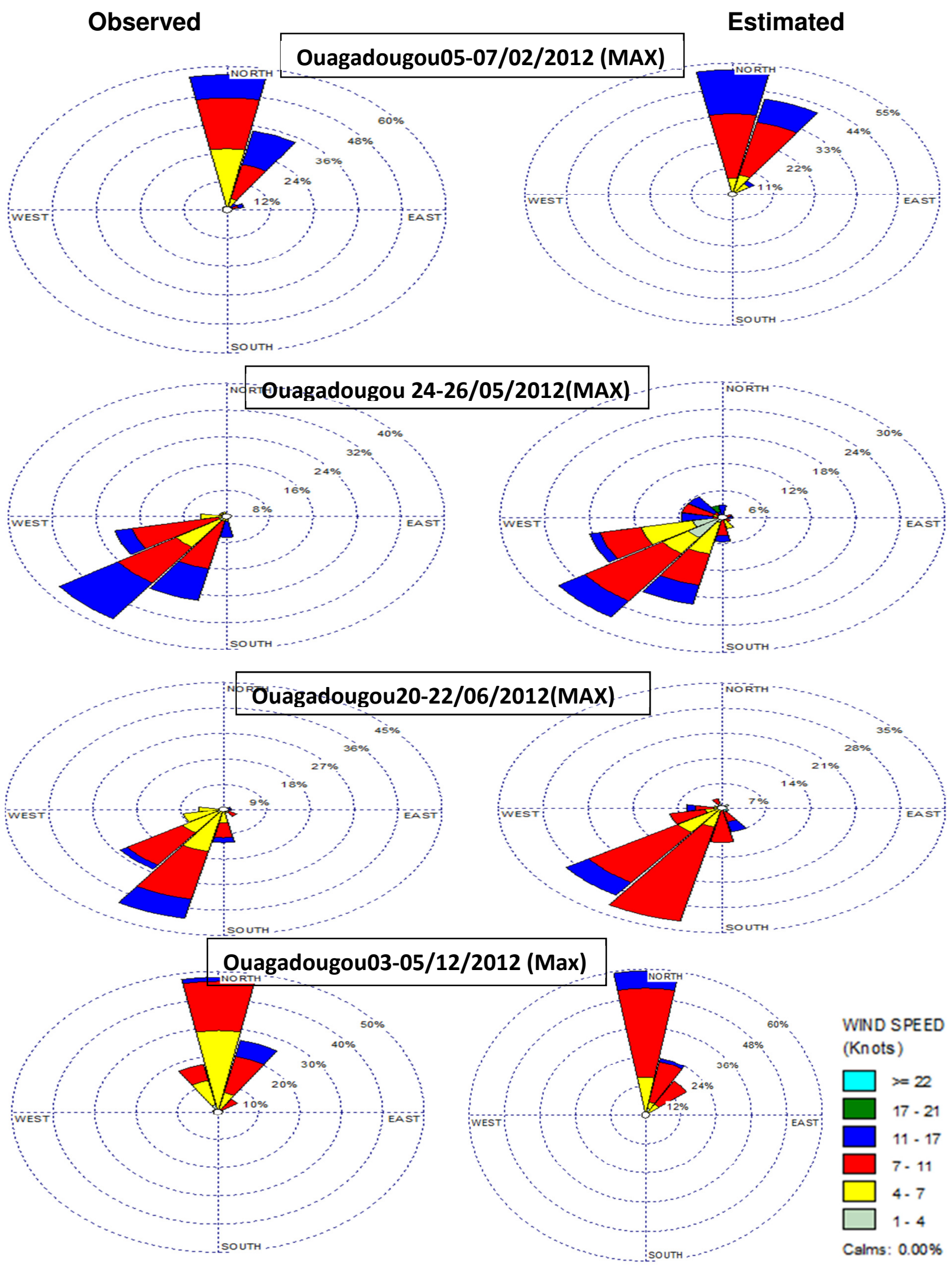

Fig. 6a. Comparison of difference between observed and estimated maximum wind speed and wind direction at four different times through year 2012 for

Ouagadougou, Burkina Faso using wind rose plot. 

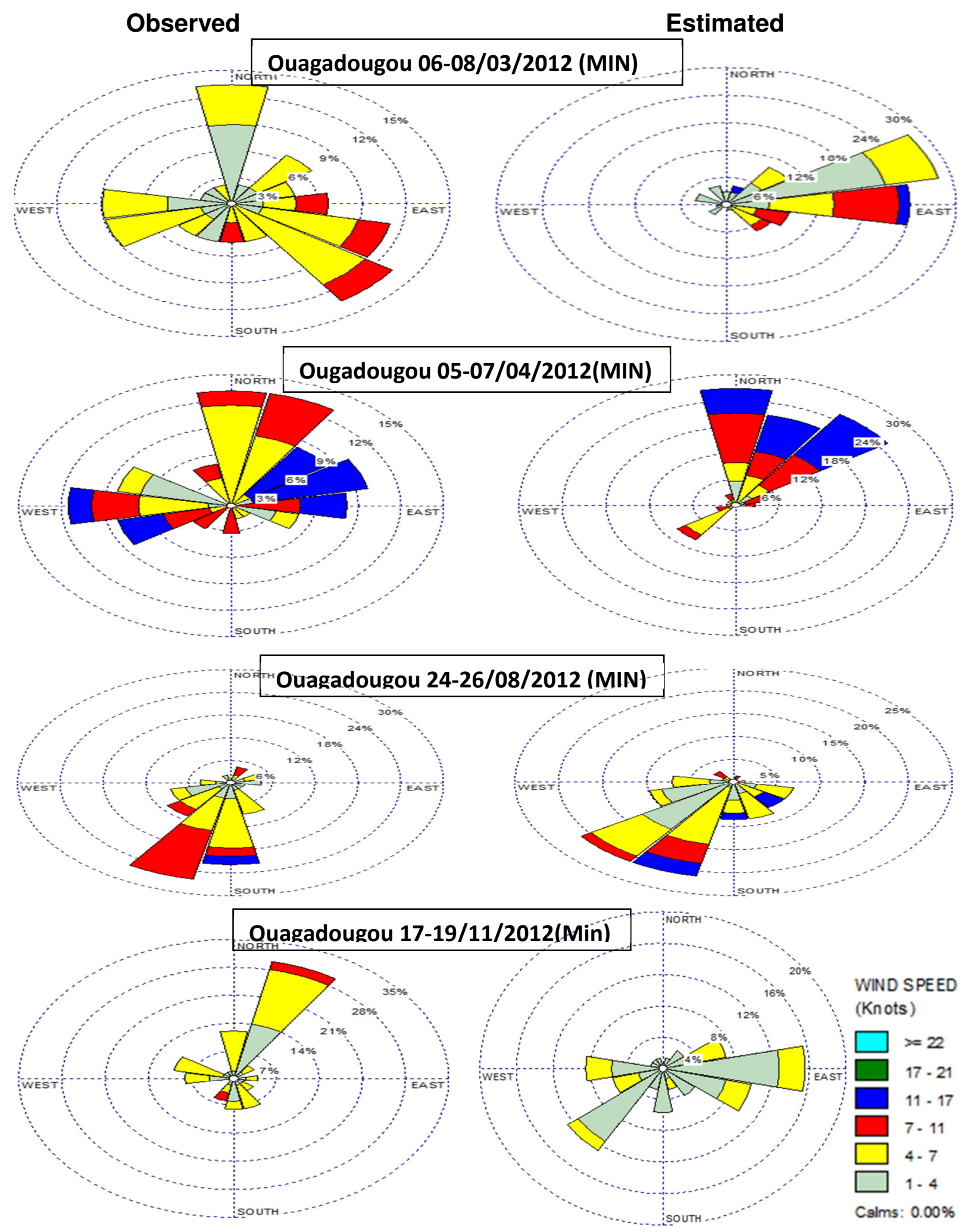

WIND SPEED (Knots)

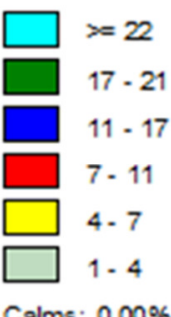

Fig. 6b. Comparison of difference between observed and estimated minimum wind speed and wind direction at four different times through year 2012 for Ouagadougou, Burkina Faso using wind rose plot. 